\title{
TRANSPORT AND STABILITY STUDIES ON TFTR
}

K.M. McGuire, V. Arunasalam, C.W. Barnes' ${ }^{1}$, M.G. Bell, M. Bitter, H.S. Bosch 2 , N.L. Bretz, R. Budny, C.E. Bush ${ }^{3}$, A. Cavallo, P. Colestock, S.L. Davis, D.L. Dimock, H.F. Dylla, P.C. Efthimion, A. Ehrhardt, R.J. Fonck, E. Fredrickson, R. J. Goldston, G. Greene, B. Grek, L.R. Grisham, G. Hammett, R.J. Hawryluk, H.W. Hendel, KW. Hill, E. Hinnov, R.B. Howell ${ }^{1}$, R.A. Hulse, H. Hsuan, K.P. Jaehnig, D.L. Jassby, F. Jobes, D.W. Johnson, L.C. Johnson, R. Kaita, S.J. Kilpatrick, R.J. Knize, G. Kuo-Petravic, P.H. LaMarche, D.M. Manos, J. Manickam, D.K. Mansfield, M.P. McCarthy, R.T. McCann, D.C. McCune, D.H. McNeill, D.M. Meade, S.S. Medley, D.R. Mikkelsen, A. Miller, W. Morris 4 , D. Mueller, E.B. Nieschmidt ${ }^{5}$, D.K. Owens, H. Park, N.Pomphrey, A.T. Ramsey, M.H. Redi, A.L. Roquemcre, T. Saito ${ }^{6}$, N.R. Sauthoff, G. Schilling, J. Schivell, G.L. Schmidt, S.D. Scott, J.C. Sinnis, J. Stevens, W. Stodiek, B.C. Stratton, G.D. Tait, G. Taylor, J.R. Timberlake, H.H. Towner, M. Ulrickson, S. von Goeler, R. Wielund, M. Williams, K-L. Wong, S. Yoshikawa, KM. Young, M.C. Zarnstorff, and 3.J. Zweben

Princeton University, Plasma Physics Laboratory

P.O. Box 451, Princeton, New Jersey 08543 USA

1 Los Alamos National Laboratory, NM, USA

2Max-Planck-Institut fur Plasmaphysik, Garching, Germany

${ }^{3}$ Oak Ridge National Laboratory, Oak Ridge, TN, USA

${ }^{4}$ Balliol Colkege, University of Oxford, UK

$5_{\text {EG\&G, Idaho, USA }}$

6Japan Atomic Energy Research Institute, Naka-machi, Japan

\section{ABSTRACT}

During the 1987 run, TFTR reached record values of $Q_{D D}$, neutron source strength, and $T_{i}(0)$. Good confinement together with intense auxiliary heating has resulted in a plasma pressure greater than $3 \times 10^{5}$ Pascals on axis, which is at the ballooning stability boundary. At the same time improved diagmostics, especially ion temperature profile measuremenis, have led to increased understanding of tokamak confinement physics. Ion temperature profiles are found to be much more peaked than previously thought, implying that ion thermal diffusivity, even in high ion temperature supershot plasmas, is greater than electron thermal diffusivity. Based on studies of the effect of beam orientation on plasma performance, one of the four neutral beamlines has been re-oriented from injecting co-parallel to counter parallel, which will increase the available baianced neutral injection power from $14 \mathrm{MW}$ to $27 \mathrm{MW}$. With this increase in balanced beam power, and the addition of $7 \mathrm{MW}$ of ICRF power it is planned to increase the present equivalent QDT of 0.25 to close to break-even conditions in the coming run. 


\section{INTRODUCTION}

The physics objective of TFTR is the study of plasma phenomena at break-even conditions. Studies of reactor-relevant alpha-heating experiments $\left(Q_{t h} \geq 2\right)$ are beyond the planned experimental scope of TFTR. However, studies of the confinement and stability properties of plasmas with fully reactor-equivalent alpha particle populations can be performed with total $\mathrm{QDT}_{\mathrm{D}}=1$, and seem to be within the anticipated operating range of high power, high-Q TFTR "supershots." Achieving $Q_{D T}=1$ in TFTR requires good plasma confinement ( $\tau_{E}=250 \mathrm{~ms}$ ) at high plasma heating powers $\left(P_{\text {heat }}=P_{\text {inj }}+P_{R F}=30 \mathrm{MW}\right.$ ). If the confinement remains independent of $P_{\text {heat }}$ and scales modestly with $I_{p}$ in the supershot regime, then this goal should be attainable.

During the 1987 run period we explored a number of plasma regimes that held promise for attaining the conditions necessary to reach $Q_{D T}=1$. Ion temperatures, $T_{j}(0)=30 \mathrm{keV}$, (measured with charge exchange recombination spectroscopy (CHERS), and $x$-ray crystal spectrometer diagnostics) and values of the product $\mathrm{nD}_{\mathrm{D}}(0) \mathrm{r}_{\mathrm{E}}(\mathrm{a}) \mathrm{T}_{\mathrm{j}}(0)=2 \times 10^{20} \mathrm{keV} \mathrm{s}^{-1} \mathrm{~m}^{-3}$ have been obtained in the supershot or "neutron-intense" regime. In this regime near-balanced neutral beams are injected into a low-density target plasma at modest current $\left(I_{p}<1.1 \mathrm{MA}\right.$ ). The good performance resulted in part from more deeply penetrating beans having better species mix ( $E_{\text {inj }}$ up to $120 \mathrm{keV}$ with $68 \%$ of the beam power in the full energy component). The new beam sources also provided longer pulses than were used during $1986(0.5 \rightarrow 2.0 \mathrm{~s})$ making possible studies of current ramps to extend the range of plasma currents which sustain the favorable profiles [broad $T_{e}(r)$, peaked $\left.n_{e}(r]\right)$ characteristic of supershots. The plasma conditions of temperature, density, and confinement time obtained go far in the low-density experiments would yield $Q_{D T}=0.25$ if an optimum fraction of the deuterium fuel were replaced by tritium and if deuterium and tritium beams were used.

The detrimental efiects of resistive MHD modes, including the sawtooth effect on confinement, were eliminated by influencing the q-profile, e.g., by beam and presuure-driven currents. The details of this MHD-free, high-reactivity operating regime will be discuseed in the following. It appears that the level of reactivity can be increased considerably, thus raising the value of $Q_{D T}$. by exploring higher beam power simultaneously with the higher plasma currente available in TFTR.

\section{OPTIMIZATION OF Q}

With 'supershots' (Strachan, 1987), TETR has reached its highest equivalent $Q_{D T}$ and record ion temperatures. The enhanced regime of plasma corfinement, known as the supershat regime, was first identified in June 1986. Supershot performance is characterized by high energy confinement times, $\tau_{\mathrm{E}} \leq 190 \mathrm{~ms}$ [ -3 times L-mode scaling (Goldston, 1984)], profile modifications [broad $\mathrm{T}_{\mathrm{e}}(\mathrm{r})$, narrow $\mathrm{n}_{\mathrm{e}}(\mathrm{r})$ ), high centra] jon temperatures (up to $30 \mathrm{keV}$ ), and large neutron source strength (up to $1.8 \times 10^{16}$ neutrons/s). A recent re-calibration of the neutron detection system indicates that the neutron source strength obtained during the last two years is higher than previously stated. Some aspects of the calibration results are not well understood, so the error bars are at p.esent substantial $(+50 \%,-30 \%)$, but in the future should be reduced to $\sim 10 \%$ 
by more extensive calibrations. With this recent calibration, the neutron emission and $Q_{D D}$ values previously quoted for 1986 need to be increased by 1.36 and for 1987 by 1.68 . The best equivalent $Q_{D T}$ obtained on TFTR during the past run period is $=0.25$ with a $Q_{\text {th }}=0.07$, assuming both $\mathrm{D}$ and $\mathrm{T}$ neutral beam injection. $\mathrm{Q}$ increases approximately linearly with balanced bearn power up to $P_{i n j}=14 \mathrm{MW}$, the highest balanced $P_{i n j}$ obtained so far. During the present experimental run period we will attempt to employ higher $I_{p}$ and the increased balanced beam power of $27 \mathrm{MW}$ to increase equivalent $\mathrm{QQT}_{\mathrm{QT}}$ to approximately 1.

To date, limits on available balanced neutral injection power have restricted supershots to low plasma currents. Figure 1 indicates the parameter range of supershots at present. The best results have been obtained with nearly balanced beam injection (12-14 MW) at a plasma current of 0.8-1.0 MA (Bitter, 1987). At these parameters a $Q_{D D}$ of approximately $1.3 \times 10^{-3}$ has been reached, with central ion temperatures of $30 \mathrm{keV}$. An experimentally observed limit of $\beta_{p}=2.0$ (McGuire, 1986) places an upper limit on the beam power which can be stably absorbed at a given plasma current. Experimentally, the beta limit is usually observed as either a plasma disruption or for qcyl <6, a beta saturation correlated with coherent MHD activity (Morris, 1987). On the other hand, an increasing threshold of balanced beam power required to obtain supershot profile characteristics with increasing plasma current has limited the maximum plasma current at which supershots can be made with the previously available balanced beam power.

A technique has been investigated (Bitter, 1987) whereby beam power and $I_{p}$ are programmed to ramp-up simultaneously, in an attempt to maintain the desirable supershot profile shapes and to avoid the deleterious coherent MHD activity. These experiments have shown promise in extending stable operation to higher beam power, but the available beam configuration in TFTR during the 1987 run (2 co-beamlines, 1 counter-beamline) still imposed a constraint that beyond $P_{\text {inj }}=14 \mathrm{MW}$, the beam power became progressively more unbalanced. Because supershot performance is optimized with near-balanced injection, the full benefit of dual current and beam power ramps will be realized only in experiments this year, following reorientation of the beamlines to provide $27 \mathrm{MW}$ balanced power.

\section{a-PARTICLE PHYSICS ON TFTR}

TFTR can be used to study reactor-relevant alpha particle physics. These results will be important as they will affect the predictions of alpha particle heating efficiency, plasma confinement, or plasma beta limits in future ignited plasmas. Most of this new physics concerns the influence of the high energy alpha particle component on plasma instabilities, and so involves parameters such as $n_{\alpha} / n_{e}$ and $\beta_{\alpha}$. These parameters depend dominantly on temperature, and can also be expressed as,

$$
\frac{\mathrm{n}_{\alpha}}{\mathrm{n}_{\mathrm{e}}} \propto \frac{\mathrm{P}_{h} Q \mathrm{~T}_{\bullet}}{\mathrm{n}_{\bullet}^{2} \mathrm{~V}}
$$

and

$$
\beta_{\alpha} \propto \frac{P_{h} Q T_{0}}{n_{e} B^{2} V}
$$


wiere $V$ is the plasma volume and the parameters $n_{\alpha} / n_{e}$ and $\beta_{\alpha}$ are related to the alpha thermalization time $\tau_{\alpha}-\mathrm{T}_{\mathrm{e}} / \mathrm{n}_{\mathrm{e}}$ (including ion drag evaluated at $\mathrm{T}_{\mathrm{e}}=10 \mathrm{keV}$ and alpha source rate $\mathrm{S}_{\alpha}-\mathrm{P}_{\text {heat }} \mathrm{Q}$, which explain the dependences shown above. Thus one sees that the best alpha particle physics parameters are obtained with high heating power, high $T_{e}$, and low plasma density which achieve high $Q$ in a small plasma volume. Simulations predict that TFTR can produce $n_{\alpha}(0) / n_{e}(0)=\beta_{\alpha}(0)=1 \%$ (Zweben, 1987) which is about reactor level (for comparison, current ITER parameters are $\left.n_{\alpha}(0) / n_{\mathrm{e}}(0)=0.7 \%, \beta \alpha(0)=2.3 \%\right)$. At these levels it is possible to study collective alpha particle instability physics which are potentially relevant for ignited plasmas. Escaping alpha particle probes which detect alphas leaving the plasma with erergy greater than $1 \mathrm{MeV}$, and the CHERS diagnostic which can measure profiles of the alpha distribution function below $0.5 \mathrm{MeV}$, will be used to study alpha particle transport. Instability effects will be studied with a $60 \mathrm{GHz}$ microwave scattering system, RF emission, and RF magnetic probes.

\section{TRANSPORT AND CONFINEMENT}

Charge-exchange recombination spectroscopy measurements of ion temperature and rotation speed profiles, made in conjunction with a radially directed diagnostic neutral beam, have provided new insight into fundamental transport mechanisms in TFTR. The ion temperature profiles over a wide range of auxiliary heating conditions are significantly narrower than expected from neoclassical transport. Transport analysis of the $T_{e}(r), T_{i}(r)$, and $v_{\phi}(r)$ profiles indicates that the heat and momentum diffusivities $\chi_{e} \chi_{j}$, and $\chi_{\phi}$ are all comparable in magnitude and have simjlar shapes in minor radius. Typically they are ordered: $x_{e}<x_{i} \leq x_{\phi}$.

Figure 2a shows the measured ion temperature profile for a supershot with nearly balanced injection $\left(I_{p}=0.5 \mathrm{MA}, P_{i n j}=13.6 \mathrm{MW}, \overline{n_{e}}=2.5 \times 10^{19} \mathrm{~m}^{-3}\right)$. Power balance calculations were performed by the 1-D SNAP kinetic analysis code, assuming a global particle confinement time of $100 \mathrm{~ms}$ (based on absolute $D_{\alpha}$ measurements), and assuming that energy transport due to particle convection is given by $\Gamma_{\text {heat }}^{\alpha}=1.5 \times T_{i} \times \Gamma_{\text {particle. }}$. As shown in Fig. $2 b$, the infersed ion thermal diffusivity was somewhat larger than the electron thermal diffusivity and showed a similar variation in minor radius. The inferred $\chi_{i}$ was much larger than the neoclassical value in the outer $70 \%$ of the plasma. These observations are consistent with previous ion power balance analyses on the D-III tokamak (Groebner, 1986). Owing to the high electron temperature in TFTR, the electron-ion power coupling is a small term in the ion power balance; within $r=\mathrm{a} / \mathbf{2}$, the dominant ion power losses are ion conduction and convection.

The SNAP steady-state kinetic transport code was also used in a predictive mode to calculate an expected ion temperature profile, given the measured $T_{e}(r)$ and a specific model for ion energy transport. The calculated ion temperature profile using $\chi_{j}(r)=1.5 \times \chi_{e}(r)$ was in reasonable agreement with the measured $T_{j}(r)$ (Fig. 2a), in contrast to the neoclassical based model $\left(\chi_{j}=3 \times \chi_{j}{ }^{\text {neo }}\right)$ which predicted an overly broad $T_{j}(r)$ profile.

Figure 3a shows the measured ion temperature and rotation speed profiles as a function of minor radius for a co-injection, $11 \mathrm{MW}$ discharge at $I_{p}=0.9 \mathrm{MA}, \bar{n}_{e}=1.7 \times 10^{19} \mathrm{~m}^{-3}$. The strong rotation in this discharge $\left(v_{\phi}(0)=8 \times 10^{5} \mathrm{~m} / \mathrm{s}\right)$ significantly alters the calculated beam power deposition and the ion power balance (Bitter, 1987 and Scatt, 1988). Beem slowing-down times are reduced substantially because the beam ions have a reduced velacity in the plasma frame of reference; consequently much less beam power is delivered to the electrons. Indeed in the 
plasma frame at the magnetic axis, the beam component at one-third energy $\left(\bar{E}_{\mathrm{o}} / 3=32 \mathrm{keV}\right)$ is approximately at the mean thermal ion energy $\left(1.5 \times \mathrm{T}_{\mathbf{i}}-30 \mathrm{keV}\right)$, so this component is assumed to be thermalized immediately. A considerable fraction of the beam power $(-30 \%)$ is invested in pushing the plasma at $r=0$, and is returned to the thermal components as viscous ion heating (Goldston, 1985). This viscous heating, which is largest at the point of maximum velocity gradient, peaks off-axis and in the calculations is responsible for the appearance of an off-axis peak in ion temperature at $r_{\text {minor }} \approx 0.2 \mathrm{~m}$, in agreement with experiment.

The inferred thermal diffusivities for electrons and ions, together with the momentum diffusivity inferred from a momentum power balance, are shown in Fig. 3b. An important observation is that the momentum diffusivity is comparable in magnitude to the ion thermal diffusivity, and has a similar variation with minor radius (Scott 1987, 1988; Fonck 1988). Within $r<2 a / 3$, the momentum balance is strongly dominated by viscosity, with convection and charge-exchange losses remaining relatively small. The thermal momentum confinement time for this co-injection only discharge was $36 \mathrm{~ms}$, about 1/2 of the thermal energy confinement time, which was $66 \mathrm{~ms}$ (the total energy confinement time, including the significant beam contribution, was $130 \mathrm{~ms}$ ). In other co-injection discharges at different powers and plasma currents, and in supershots, the thermal momentum confinement time ranged from 20 to $94 \mathrm{~ms}$. As a fraction of the thermal energy confinement time the momentum confinement time was in the range $0.4-0.7$. The systematic correlation between $\chi_{\phi}$ and $\chi_{i}$ points toward a transport mechanism that affects ion heat and momentum transport similarly (Lee and Diamond, 1986).

The supershot regime on TFTR shows evidence of substantial nonohmically driven toroidal current, even for balanced beam momentum input. It has been found necessary to include the bootstrap current in data analysis runs using TRANSP (Goldston, 1981) in order to model the magnitude of surface voltage reversal during high- $\beta_{p}$ supershots with nearly balanced co- and counter-tangential beam injection (Zarnstorff, 1988a). For the case of balanced injection with $\beta_{p}=2$ the maximum calculated bootstrap current is $=0.5 \mathrm{MA}$ out of a total $\mathrm{I}_{\mathrm{p}}=0.9 \mathrm{MA}$. Co-tangential neutral beam injection of $11 \mathrm{MW}$ alone has been used to drive - $1 \mathrm{MA}$ for 2 seconds, and has resulted in partial recharging of the ohmic heating transformer for an $I_{p}=0.9$ MA plasma. Figure 4 shows the results of calculations with the time-dependent $1 / k-D$ transport analysis code TRANSP: three models are used to predict the measured surface voltage. From the figure it is clear that the model which includes both the beam and bootstrap driven currents in addition to the ohmic current best fits the data. While the driven currents do not exceed the total current, the calculated voltage is negative because the radial distribution of the beam and bootstrap current is broader than that of the ohmic current, exceeding the total current density in the outer region of the plasma.

\section{SUPERSHOT STABILITY, BETA LMMITS, AND MHD}

High power balanced injection experiments on TFTR have revealed a beta limit with significantly different parametric dependence from that expected on the basis of results from other tokamaks. Figure 5 shows $\beta_{n}\left(\equiv \beta_{0} D I A\right.$ aB/ $\left.\mu_{0} I_{p}\right)$ (Troyon, 1986) for supershot type plasmas on TFTR versus $q_{\text {cyl }}$. Diamagnetic $\beta_{\phi}$ DIA is used in Fig. 5 , and since the NBI is tangential, this underestimates the total stored energy. It is seen that there is a clear fall of the achievable $\beta_{n}$ with $q_{\mathrm{cyl}}$. Coherent MHD activity is often seen in these high $\beta_{p}$ discharges. Mode numbers of the MHD oscillation observed on some of the discharges are also shown in Fig. 5, along with the 
discharges which disrupted. For $q_{c y l}$ below 6 , the $\mathrm{m} / \mathrm{n}=1 / 1$ mode is most often observed and above $q_{c y l}-6$ the $\mathrm{m} / \mathrm{n}=2 / 1$ and $3 / 2$ modes are dominant. The $\beta_{p}$ limit is frequently disruptive: degraded confinement is also seen but not in the discharges that end with a disruption. Sawteeth are mostly absent for high $q_{c y l}$ discharges during injection. When sawteeth are present, however, there are no coherent low-m modes. It should be noted that TFTR L-mode and ohmic discharges are generally entirely free from coherent low-m MHD activity. Disruptions at the $\beta$-limit usually show no conventional precursor to the energy quench, however an odd-m mode is sometimes observed to grow on a $50 \mu$ s time scale. The energy quench is very rapid compared to resistive time scales. The time scales of the mode growth and energy quench suggest that a conventional picture of multiple helicity tearing modes leading to global stochasticity is not appropriate. The conflict of time scales here is reminiscent of the sawtooth instability (McGuire, 1985).

The most interesting results from the coherent MHD activity is the observation of continuous $n=$ 2 oscillations in the absence of any $n=I$ activity. Figure 6 a shows the time behavior of a well-behaved supershat with low amplitude coherent MHD activity. Analysis of the phase of the Mirnov signals with a first order toroidal correction yields $m / n=3 / 2$ (Fig., (b) with remarkable purity in most cases. The 60-channel horizontal soft X-ray camera shows that the mode is limited to $\mathrm{r}<30 \mathrm{~cm}$ with a complex structure consistent with $\mathrm{m}=3$. A phase change near the resonant surface suggesta a helical flattening of the emission profile (possibly a magnetic island) which is confirmed by ECE data. Although this mode is most unambiguously observed in the absence of $n=1$, the frequency of the mode is generally twice that of $m / n=2 /$ modes observed in similar discharges, and $f_{\text {mode }} \leq 2 f_{\text {rot }}(0)$. The mode is present in many supershot plasmas at a low level, but at large amplitudes its presence is correlated with degraded confinement (see Fig. 6b). Estimates of the width of the magnetic island may be made using cylindrical tearing mode eigenfunctions, together with the mensured field perturbation at the wall. $A$ width of $10 \mathrm{~cm}$ at $\mathrm{r}=30 \mathrm{~cm}$ is typical when there is confinement degradation. The familiar $\mathrm{m} / \mathrm{n}=2 / 1$ mode is also obseryed, and it is usually associated with even greater degradation of confinement (Fig. 6c). Again it is very clearly identified from the phase of the Mirnov oacillations at the wall. The SXR signals often show a small coupled odd-m component at the same frequency near the axis, but the magnetic structure supports the $m=2$ identification. This mode occurs less often than the $\mathrm{m} / \mathrm{n}=3 / 2$ mode, and usually has a larger amplitude than the $\mathrm{m} / \mathrm{n}=3 / 2$ mode. The inferred island size is found to be $=15 \mathrm{~cm}$. Flattened regions of this order have been identified on the $T_{e}$ $(r)$ and the $\mathrm{n}_{\mathrm{e}}(\mathrm{r})$ profiles measured by the Thomson scattering system (Fredrickson, 2988).

At values of $\varepsilon \beta_{p}-1$ it is expected that high-n ballooning modes should become unstable, so TFTR profiles have been analyzed for ballooning stability. The measured $P_{\theta}(r)$ and $T_{i}$ profiles are combined with calculated $\mathrm{Pb}_{\mathrm{b}}(r), \mathrm{P}_{\mathrm{j}, \mathrm{th}}(r)$ to give the total plasma pressure. The calculation is performed with the TRANSP code, or the 1-D SNAP kinetic analysis code. The result using the S-a technique (Lortz, 1978) with a large-aspect-ratio model equilibrium, is that TFTR high $\beta_{\text {pol }}$ discharges often lie at the stability limit over most of the eross-section, and sometimes are slightly unstable (see Fig. 7). The largest dp/dr occurs in the discharges with the best confinement. It should be stressed that most of the pressure gradient (typically 50\%) is due to the fast-ion component, and if the calculated thermal pressure gradient alone is used, the plasma is well below the stability boundary.

Analysis of the high-n ballooning mode stability with the fully toroidal PEST code (Dobrott, 1977) reveals instability in some cases. Although these computations predict instability, the $\mathbf{n}_{\text {critical }}$ 
may be so high $(>20)$ that kinetic effects may be important. (although not necessarily stabilizing). For a typical TFTR high $\beta_{p}$ plasma, the finite Larmor radius perameter $\Lambda_{F L R}$ is above unity for $n>5$. The cunclusion is that high- $n(n<5)$ ballooning modes are predicted to be unstable in the highest $\beta_{p}$ plasmas over a part of the profile, and may play a role in the initiation of the high-beta disruptions. High-n modes are not observed experimentally near the beta limit, implying that they are probably not involved in the period of poor confinement when the energy content and neutron flux are falling.

The PEST-2 code (Grimm, 1983) has also been used to investigate many discharges close to the experimental $\beta$-limit for stability to low- $n$ ideal modes. The results indicate that the plasmas may be unstable to an $n=1$, but are stable to $n=2$ for all cases tried. The $n=1$ stability depends on the assumed position of an external conducting wall and the precise value of $q_{0}$. Both internal and external kinks may be observed (the latter requiring a vacuum region for instability). The internal kink growth rate increases rapidly from zero as $q_{0}$ falls below unity, and so is an attractive candidate for disruptions with very little precursor activity, as discussed above. The external kink is strongly coupled to the $m=1$ mode, becoming gradually more unstable as $q_{0}$ is reduced. In both cases the mode structure is of the usual coupled-m form, with $m=1$ dominating in the core. A cylindrical delta-prime code (Fredrickson, 1988) and the PEST-3 code (Grimm, 1982) have also been used to study the resistive MHD mode stability of TFTR aupershots close to the $\beta p=2$ disruption limit as well as other discharges that have coherent MHD activity. The results show that many of the discharges are close to marginal stability for the $\mathrm{m} / \mathrm{n}=2 / 1$ mode but that the $m / n=3 / 2$ is stable in all cases studied. The results from PEST-3 with the pressure and toroidal terms retained show similar results to those of the cylindrical, zero-pressure delta-prime code, indicating that pressure and toroidal effects are not a significant factor in the resistive stability of these discharges. The effects of non-ohmic currents in the plasme may play an important role in the resistive stability. From the TRANSP code it is found that the current profile has a tendency to broaden during supershots and that the $q$ on axis may rise above 1; even so, the profiles are not calculated to be unstable to the $m / n=3 / 2$. Nevertheless, experimentally the $\mathrm{m} / \mathrm{n}=3 / 2$ mode (see Fig. 5) is observed during many supershots on TFTR. From the analysis with the cylindrical delta-prime code it is found that a $r_{0}$ of approximately 1.3 is needed before the $m / n=3 / 2$ mode goes unstable. The effects of neoclassical currents on the physics of the resistive layer and on the dynamics of the magnetic island growth (Callen, 1986) are being evaluated at present.

In summary, it is found that the $\beta$ limit depends on $q_{c y l}$; the location of the experimental $\beta$-limit is consistent with an $n \rightarrow \infty$ ideal-MHD balloonitg and low-n ideal MHD kink limit, as on other devices, despite the fall in $\beta_{n}$ with $q_{c y l}$. The mode structure calculated from the PEST code is close to that observed on TFTR for the $m / n=1 / 1$ modes, and does sometimes match the $m / n=2 / 1$ fuctuations associated with the degraded confinement.

\section{SAWTEETH ON TFTR}

Many types of sawtooth activity have been identified in TFTR (McGuire, 1985): (1) simple or normal sawteeth, (2) small sawteeth, and (3) compound sawteeth. Reconstruction of the soft X-ray and local temperature measurements from ECE signals have been used to obtain information about the internal phenomenology of sawteeth on 8 fast time scale. Figure 8 shows reconstructed contour plots of local temperature using only 1-D data. This methad of reconstruction is limited 
to changes in the emission which are slow with respect to the rotation of the plasma, but are useful on TFTR due to the large rotation velocities obtained with neutral injection. The overall features of the sawtooth crash are clear from this data: (1) the hot core moves away from the center as the temperature island structure grows (see Fig. 8a); (2) when the temperature island gets to be about half the radius of the $q=1$ surface, the hot core starts to deform in shape and becomes somewhat crescent shaped (see Fig. Bb); (3) the cold temperature island "pusheg" the hot core against the $q=$ 1 surface region, and then the heat spreads poloidally around the $q=1$ surface (see Fig. 8c); (4) the temperature island grows to form the new plasma core (see Fig. 8d). This picture of the sawtooth crash is observed on many sawteeth on TFTR. The time scale for the complete crash

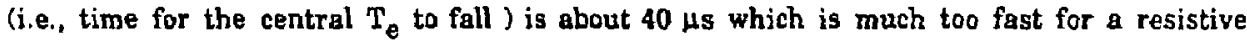
reconnection process. However, the topology of the characteristic temperature island growth and the motion of the hot core do appear to be consistent with reconnection type phenomena. Detailed study of the magnetic oscillations and the high frequency turbulence do not show enhanced levels during the crash phase of the sawtooth, as would be expected from a stochastic insdel. However, the new microwave scattering system being installed on TFTR will better address this question of turbulence during the sawtooth crash phase.

Stabilization of the sawtoath oscillation has been observed in the supershot regime for up to $2 \mathrm{~s}$, and after pellet injection for a duration of 1s. Figure 9 shows a supershot plasma with no sawteeth for 2s. Calculations using the TRANSP code with beam and bootstrap currents used in the analysis (Zamstorf, 1988a) indicate that the sawtooth stabilization is due to a broadening of the q profile which leads to $q_{0}$ rising above 1.

\section{HEAT PULSE PROPAGATION STUDIES}

Studies of the heat pulse propegation from savtooth crashes on TFTR strongly sucgest that the heat pulses are not propagating as expected based on transport coefficients derived from transport analysis (Fredrickson, 1986). While there are many models which raight explain this discrepancy, it is the opinion of some of the authors (McGuire and Fredrickson) based on results from TFTR that the discrepancy is not due to general problems with thermal tranuport, e.g., thermal pinch models, marginal stability models or the like (Fredrickson, 1986), but that the rapid heat trarsport is the result of the sawtooth crash mechanism itself. Figure 10 shows some of the so-called 'ballistic' heat pulvos seen on TFTR. For this plasma the oft X-ray line-average inversion radius is about $22 \mathrm{~cm}$ (implying a local inversion radius of $-31 \mathrm{~cm}$ ), in reasonable agreement with the electron temperature inversion radius of $34 \mathrm{~cm}$ and with current profile salculations of the $q=1$ radius. The Kadomtsev sawtooth model (Kadomtsov, 1975) would predict that the reconnection radius can extend only a short distance beyond the $q=1$ radius, as the high plasma canductivity would severely limit the amount of helical flux added between sawtooth crashes, which would be available for reconnection. This is in good agreement with fast ECE electron temperature profile measurements, which show a flattening of the temperature profile only out to about $40 \mathrm{~cm}$. Nevertheless, a very fast, poloidally asymmetric pulse of heat is observed with the sof $X$-ray camera to propagate vertically down, reaching a minor radius of at lesst 56 $\mathrm{cm}$, well outside the reconnection radius, in less than 20ys. Outside the furthest point where this initial pulse of heat was observed, the heat pulses appear to propagate "normally." This very fast initial redistribution of heat will, however, result in heat pulses which are not diffusive in nature, making the coinmon methods of heat pulse analysis invalid. While this is an extreme 
example, the possibility that a similar process occurs in all sawtooth crashes cannot be ruled out. Indeed, even small sawteeth in high $q_{c y l}$ ahmic plasmas have heat pulse shapes which are not as expected from purely diffusive simulations (Goldston, 1988).

\section{SUMMARY AND CONCLUSIONS}

Improved diagnosties on TFTR have allowed better analysis of the thermal power balance with measured electron and ion temperature profiles. The analysis shows that $\chi_{i}=2 \chi_{e}$.and that $\chi_{\phi}=$ $(1-2) \chi_{i}$. Substantial driven curren's have been observed which, at high $\beta p=2$, are consistent with the neoclassical bootstrap current. In addition, for unbalanced injection, there are cases where most of the current is beam-driven. In the supershot regime sawteeth can be stabilized for up to $2 s$. $A$ beta limit is found at $\beta p=2$ (or $\varepsilon \beta_{p}-0.7$ ), consistent with the kink and ballooning limit. This limit is observed as a disruption in many cases.

The main objective of the TFTR experimental plan is to obtain $Q_{D T}=0.5-1.0(-$ break-even) and to study alpha particle physics at $Q_{D T} 20.5$. TFTR has obtained a ${ }_{D}(0) r_{E} T_{i}(0)=2 \times 10^{20}$ $\mathrm{keV} \mathrm{s}^{-1} \mathrm{~m}^{-3}$ and $\mathrm{Q}_{\mathrm{DD}}=1.3 \times 10^{-3}(+50 \%,-30 \%)$ during the $1987 \mathrm{run}$ period. This result would extrapolate to a D-T plasma with $Q_{D T}=0.25$, in which $Q_{D T}$ (th- th $)=0.07$ with mixed D-T beam injection. TFTR is now in the desirable position of having high temperatures $\left(T_{1}(0)=30 \mathrm{keV}\right.$, $T_{\mathrm{e}}(0)-8 \mathrm{keV}$ which will result in alpha particle parameters close to reactor-relevant levels during D-T operation. These experiments can be used to study the physics of burning plasmas and to examine reactor-relevant collective alpha particle physics effects.

\section{ACKNOWLEDGEMENT}

This work was supported by the United States Depertment of Energy Contract No. DE-AC02-76-CHO-3C73.

\section{REFERENCES}

Bitter, M. and co-workers (1987). Plasma Physicand Controlled Fusion 29.1235.

Caller, J. D. (1986). Proc 11 th Intem. Conf. on Plasma Physics and Controlled Nuclear Fusion Research (Kyoto) Yol.11. 157.

Dobrott, D. and co-workers (1977). Phys. Rev Lett. 39, 943.

Fredrickson, E. D. and co-workers (1988). ReV.Spi. Instrum. Accepted for publication.

Fredrickson, E. D. and co-workers (1986). Nuci. Fusion 26, 849.

Fonck, R. J. and co-workers (1988). Broc.15th Buropean Conf on Controlled Fusion and Plasma Physic: Yol. L. $_{83}$

Goldston, R. J. (1981). J. Comp. Phys. 43, 61.

Goldston, R. J. (1984), Dlasma Physias and Controlled Fusion 26, 87.

Goldston, R. J. (1985). Basic Physical Processes of Toroidal Fusion Plasmas Yol 1, 165.

Goldston, R. J. and co-workers (1988). Broc 15th Erropean Conf on Controlled Eusion and Plasma_Physias Vol.1. 99.

Grimm, R. C. and co-workers (1982). Plasma Physies and Controlled Fusion. Vol.III, 35. 
Grimm, R. C. and co.workers (1983). I. Como. Phys.49, 94.

Groebner, R. J. and co-workers, (1986). Nual Fusion 26. 543.

Kadomtser, B.B. (1975). Sov.J. Plasma Phys.1, 389

Lee, G.S., and Diamond, P.H. (1986). Bhys. Fluids 29, 3291.

Lortz, D. and co-workers (1978). Phys, Lett, A68, 49.

McGuire, K. M. and co-workers (1985). Proc.12th European Conf on Centrolled Fusion and Blasma Physics Vol. I, 134.

McGuire, K M. and co-workers (1986). Broc 1t th Intern Conf on Plasma Physics and Controlled Nuclear Fusion Research (Kyoto) Vol, 421.

Morris, A. W. and co-workers (1987). Rroe 14th European Conf on Controlled Eusion and Plasma Physics Vol. I, 189.

Scott, S. D. and co-workers (1987). Broc 14th European Conf. on Controlled Fusion and Plasma Phusies Vol. 65.

Scott, S. D. and co-workers (1988). Broc 25th European Conf on Controlled Fusion and Plasma Bhysics Vol. 103

Strachan, J. D. and co-workers (1987). Bhys.Rey.Lett. 58. 1004.

Troyon, F. and co-workers (1984). Plasma Physics and Controlled Fusion 26, 209.

Zamstorf, M.C. and co-workers (1988)a. Phws.Rev._Latt,60, 1306.

Zarnstorf, M. C. and co-workers (1988)b. Broc. 15th European Conf an Contralled Eusion and Plasma Physies Yold, 95

Zweben, S. J., private communication.

\section{FIGURE CAPTIONS}

Fig. 1. Contours of the maximum $Q_{D D}$ achieved for given value of plasma current and neutral injection power. The highest value of $Q_{D D}$ was reached at $0.9 \mathrm{MA}$ with $14 \mathrm{MW}$ of NBI power corresponds to a $\mathrm{QDT}^{\mathrm{eq}}$ of 0.25 .

Fig.2a. Comparison of measured and predicted jon temperature profiles for a supershot with nearly balanced injection. The solid points are ion temperatures measured with the CHERS diagnostic. The solid curves are ion temperature profiles preficted with the assumption of various ion thermal transport models. The best fit assumes that $\chi_{i}-1.5 \chi_{\theta} \cdot\left(I_{P}=0.9 \mathrm{MA}, P_{i n j}=\right.$ $13.6 \mathrm{MW}, \overline{\mathrm{n}_{e}}=2.5 \times 10^{19} / \mathrm{m}^{3}$ ).

Fig.2b. The calculated electron and ion thermal diffusivities using meanured electron and ion temperature profiles. Also shown is a curve representing three times the calculated ion neoclassical thermal diffusivity.

Fig.3a. The ion temperature, plasma rotation, and electron temperature profiles for a co-injection, low current plasma. The open points are the ion temperature and the solid circles are the rotation velocity measured with the CHERS diagnostic. The solid line is the electron temperature profile from the Thomson scattering diagnostic. ( $I_{P}=0.9 \mathrm{MA}, P_{\text {inj }}=11 \mathrm{MW}, \overline{n_{e}}=$ $1.7 \times 10^{19} / \mathrm{m}^{3}$ ).

Fig.3b. Transport analysis of the above data showing the similarity in magnitude and profile shape of the electron and ion thermal diffusivities and the momentum diffusivity. 
Fig.4. Comparison of the calculated and measured loop voltage. The calculations including both beam driven current and bootstrap effects best reproduce the data.

Fig. 5. Regions in the $\beta_{n}, q_{c y l}$ plane, where various types of MHD activity are observed when approaching the $\beta_{\mathrm{pol}}$ limit in supershots:

$\mathrm{m} / \mathrm{n}=1 / 1:$ solid circles

$=3 / 2:$ solid triangles

$=2 / 1:$ open squares

Fig.6. Time evolution of the poloidal beta $\beta_{p}$ DIA and neutron source strength from three nearly identical discharges with $P_{\text {inj }}=10.3 \mathrm{MW}$ from 4.0 to $4.7 \mathrm{~s}$. The plasmas developed different levels of MHD activity. The confinement is degraded in the presence of $\mathrm{m} / \mathrm{n}=3 / 2$ activity and even more so in the presence of $\mathrm{m} / \mathrm{n}=2 / 1$ activity.

Fig. 7. The measured total pressure profile $P_{\text {tgt }}(r)$ during the best TFTR supershots lies very close to the high-n ideal ballooning limit profile inferred from the calculated $q$ profile.

Fig. 8. 2-D contour plots of the electron temperature unfolded from 1-D data, assuming constant plasma rotation. The contours show the evolution of a growing temperature 'island' whieh pushes the central, hot plasma core out. The hot core eventually disperses and the cool island becomes the new plasma core.

Fig. 9. The central electron temperature $T_{\theta}(0)$ as a function of time, illustrates the stabilization of sawteeth during a two second beam pulse. Sawteeth resume shortly after beam turn-off.

Fig. 10. Soft x-ray traces showing the propagation of the heat pulse from a sawtooth in a low $q_{\text {cyl }}$, beam heated plasma. The schematic temperature profile indicates the tangency radii for the soft-x-ray chords. An asymmetric pulse of heat is seen to propagate vertically down to $56 \mathrm{~cm}$ within $50 \mu$ s of the sawtooth crash. 


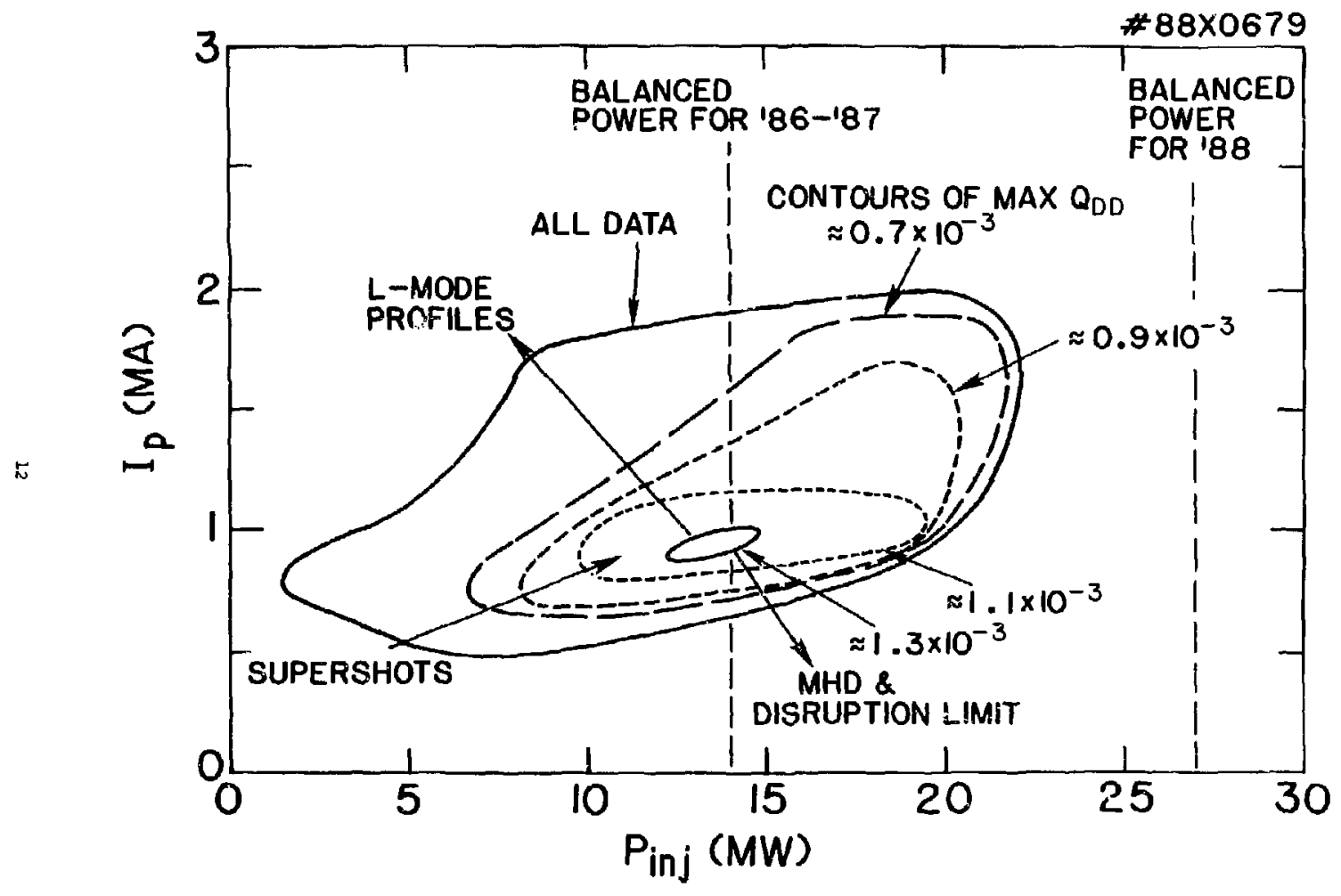

Fig. 1 

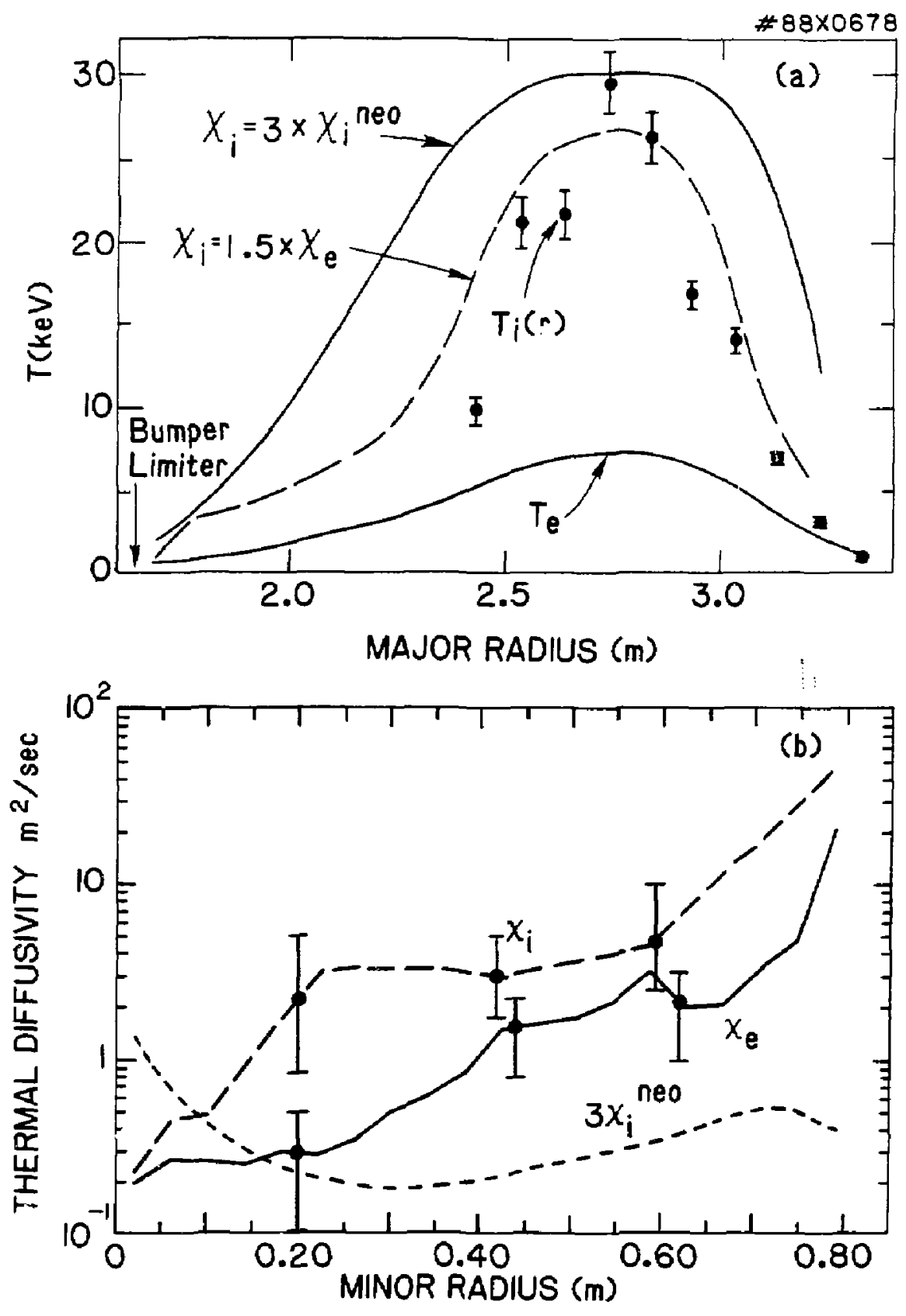

Fig. $2 b$ 


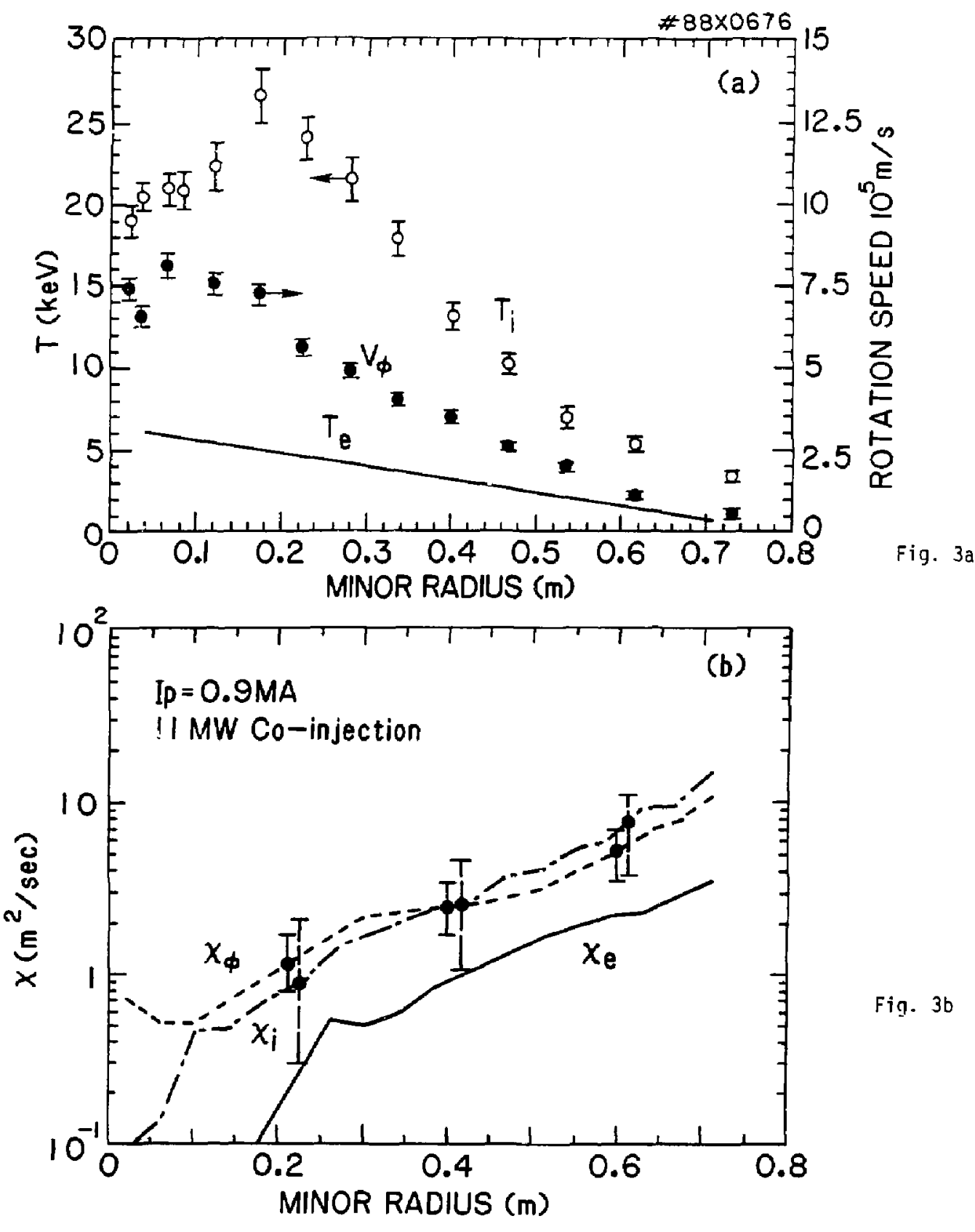


\#88X0677

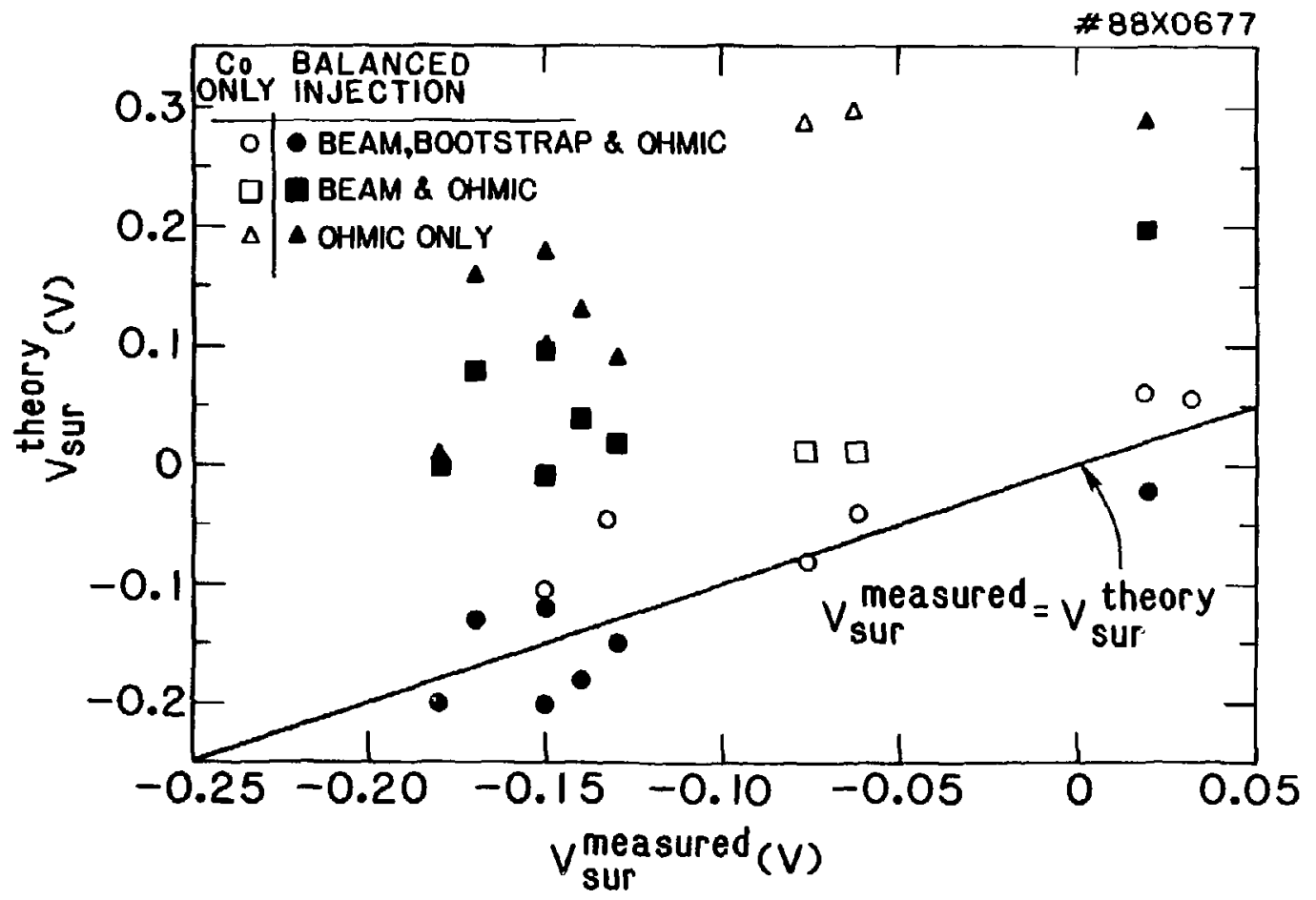

Fig. 4 


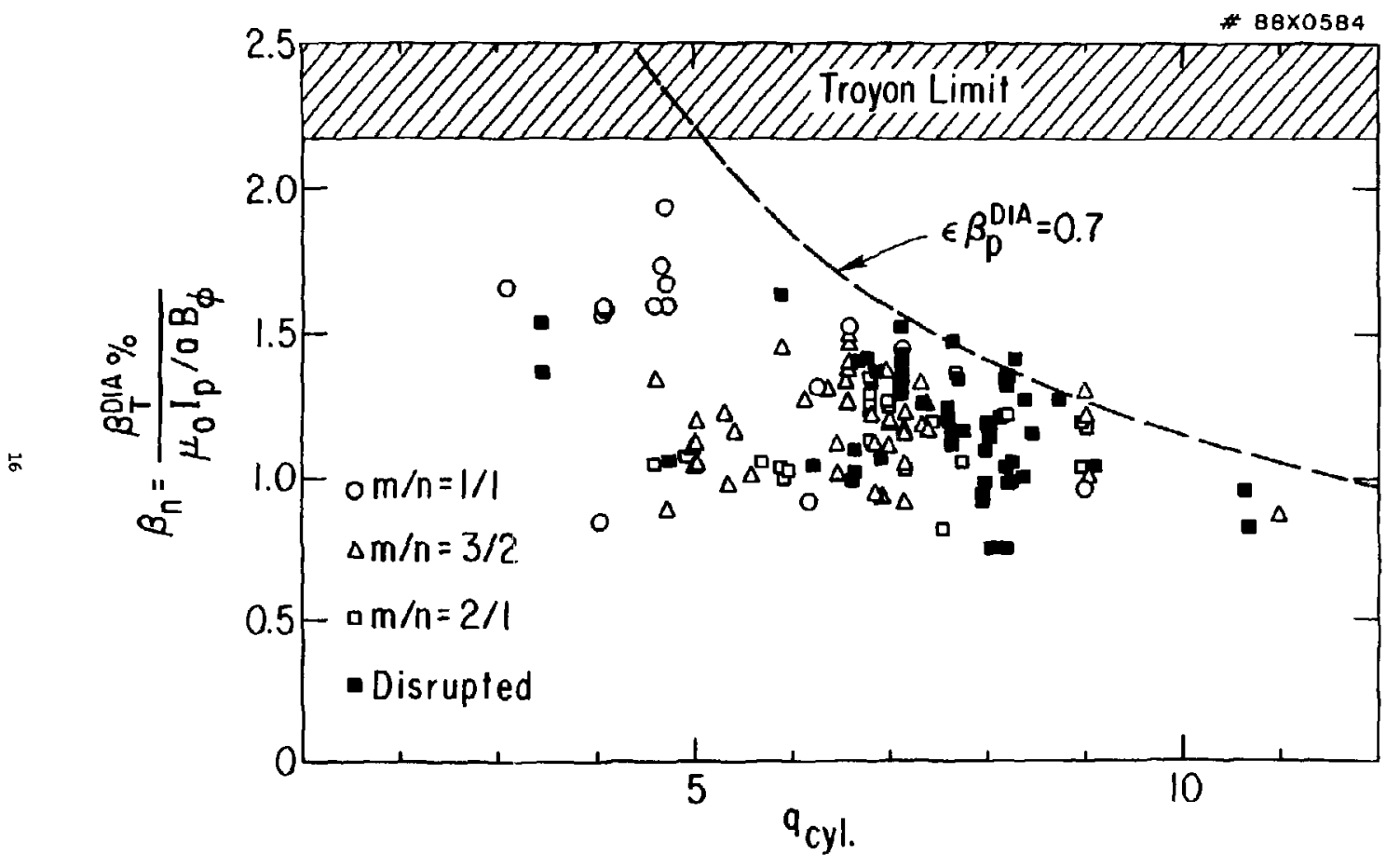



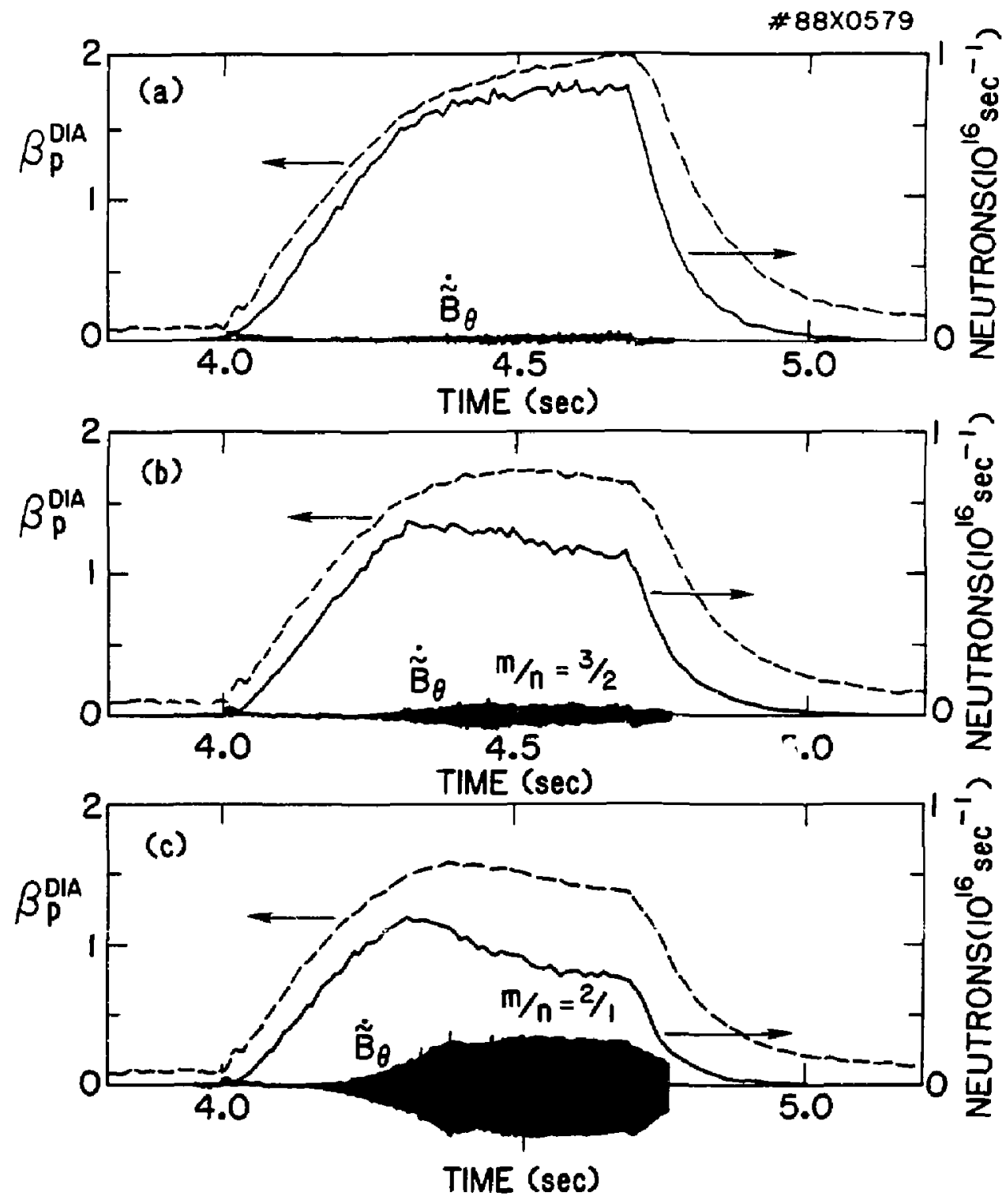

Fig. 6 


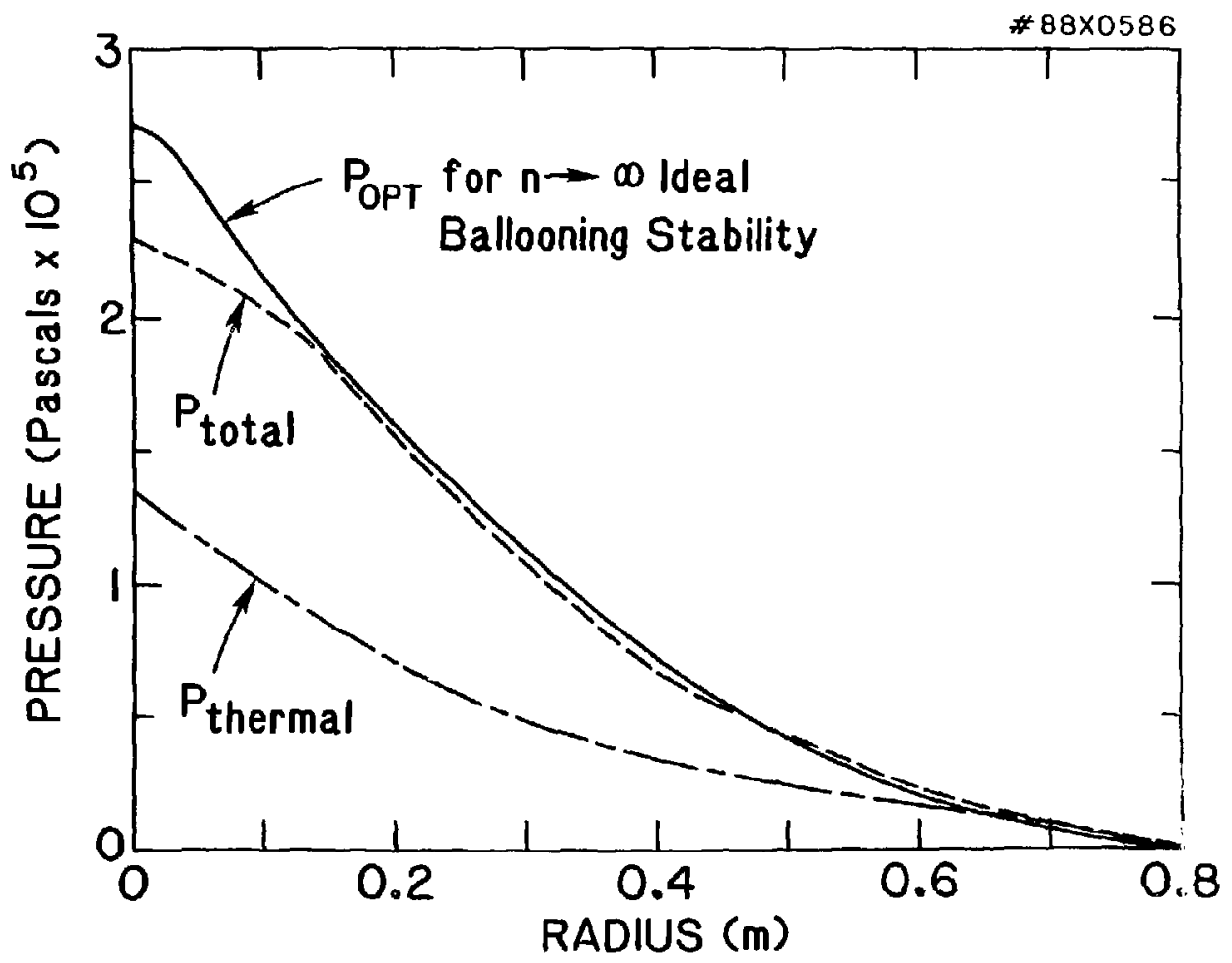

Fig. 7 

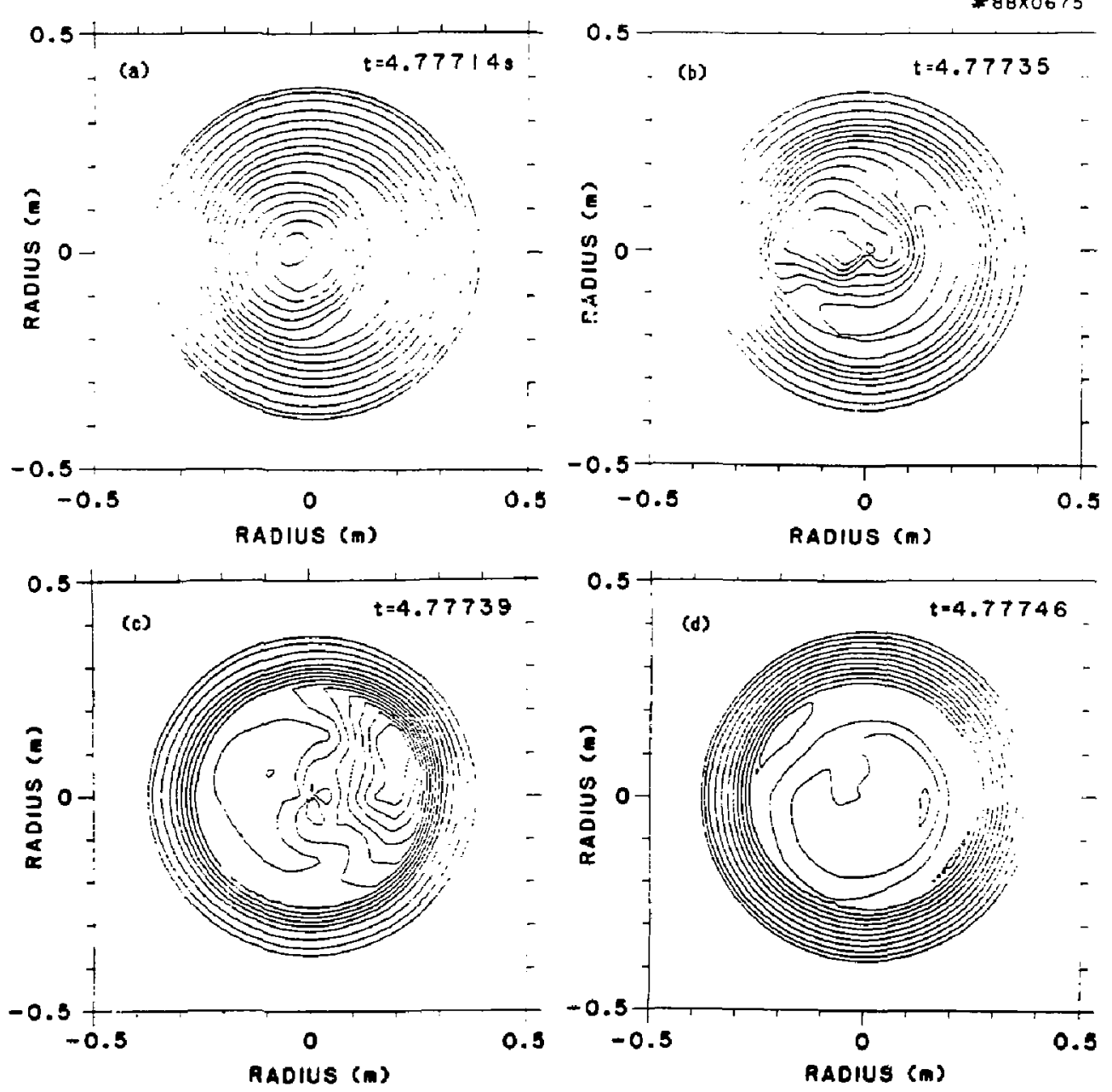

Fig. 8 


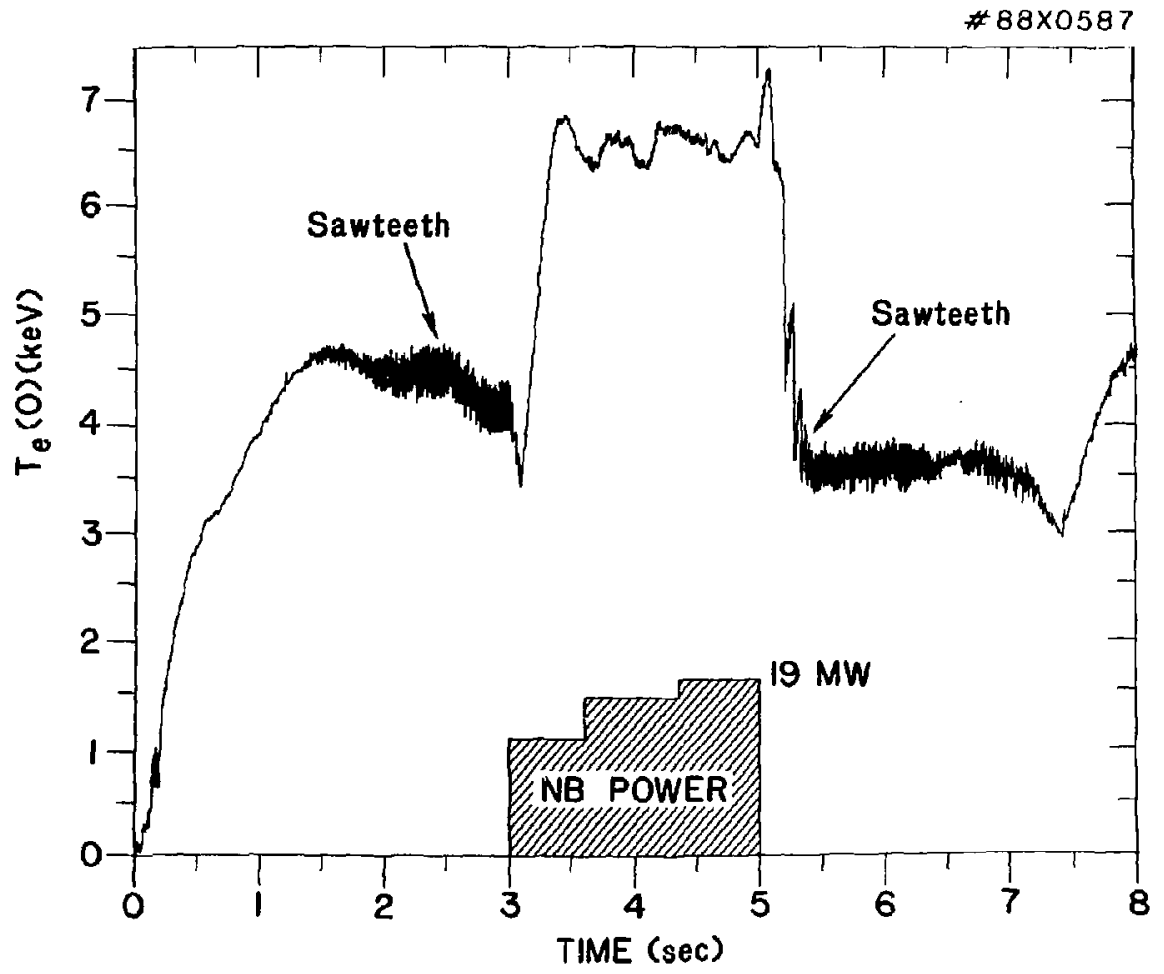

Fig. $g$ 
\#88X0680

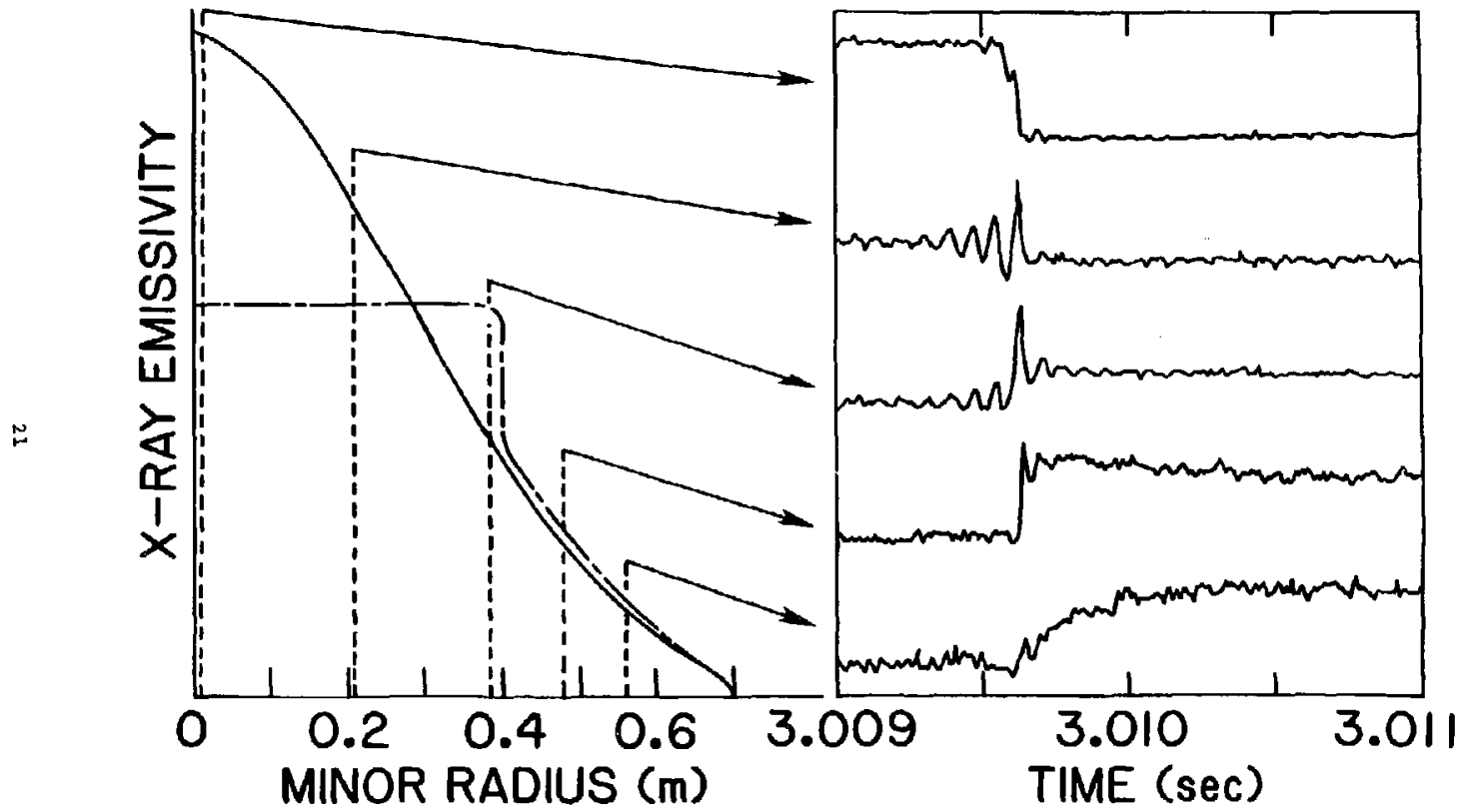


Or. Frank J. Paoloni, univ of Wol longong, AUSTRALIA Prol. M.H. Eronnan, Univ Sydney, AuSTRALIA

Plasmo Research Lab, , Australian Not, Univ., AUSTRALIA Prol. I,R. Jones, Flinders univ., AustealiA

Prol, F. Cod, Inst Theo Phys, AUSTRIA

Prot. M. Heindler, Institut tur Theoretische Physik, ALSTRIA

M. Goossens. Astronomiseh instituUt, BELGIuM

Ecole Royale Militaira, Lab de Phys Plasmas, BELGILm

Comission-European, Dg-XII Fusion Prog, BELGIJM

Prot. R. Boucique, Laboratoriun voor Natuurkunde, BELGIUM

Or. P,H. Sakanaka, Instituto Fisics, BRAZIL

Instituto De Pesquisas Espaciasi-iNPE, ERnzIL

Documents Office, Atomic Energy of Canoda Linited, Cakada

Dr. M.P. Bochyngki, MPB Technolgoies, Inc., CANADA

Dr. H.M. Skarsgard, University of Saskatchiowan, CANAOA

Dr. H. Barnard, University of British Columbia, CANAOA

Prot. J. Tolichmann, Univ. of Hontreal, CAMADA

Prot. S.R. Sreenivasan, University of Calgary, CANADA

Prot. Tudor W. Johnston, INRS-Energie, CAMADA

Dr. C.R. Jases, Univ. of Albarta, CAMAOA

Or. Peter Lukac, Komenskeho Univ, CZECHOSLOVAKIA

The Librarlan, Culham Laboratory, ENGLAkD

The Librarian, Rutherford Appleton Laboratory, ENGLANO

Mrs. 5.A. Hutchinson, JET Llorary, ENGLAND

C. Mouttet, Lab. te Physique des Milioum lonises, FRANCE

J. Raget, CEn/CAOARACHE - Bat SO6, FRANCE

Univ. of loannina, Liorary of Physics Oept. CREECE

Dr. Tom Mul, Acadeny Bibliographic Ser., HONG KOwe

Preprint Library, Hungarian Academy of Sciences, Huvakr

Dr. 8. Dasgupta, Saha Inst of Nuel. Phys., IMDIA

Dr. P. Kaw, Institute for Plasaa Rogearch, INDIA

Dr. Philip Rosenau, Israel inst. Tech, ISRAEL

Librarian, Int'I Ctr Theo Phys, ITALY

Prat. 6. Rostagni, Univ Di Podova, I TALY

Miss Clelio De Palo, Assoc Euraton-EnEA, ITALr

Bibiloteca, Instituta di Fisica del PIssad, ITALY

Or. H. Yanato, Toshiba Ras \& Dav, JAPNN

Prot, I. Kawakeni, Atomic Energy Ras. Institute, JAPAN

Prot. Kroji Mishikawa, Univ of Hiroshina, JAPAH

Direc. Dept. Large Tokeark Res. JAERI, JAPN

Prof. Sotoshi ItO.". Kyushu University, JAPAN

Rasearch Info Conter, Nagord University, JAPNN

Prof. S. Tanaka, Kyoto University, JAPAN

Library, Kyoto University, JAPAN

Prot. Nobuyuki Inoute, University of Tokyo, JAPAH

5. Nori, JAERI, JAPAN

Librarion, Kored Advanced Energy Res. Institute, KOREA

Prot. D.1. Choi, Adv. Inst Sel \& Teeh, KOREA

Prof. B.5. Liloy, Univarsity of Waikato, NEW EEALAND

Institute of Plasma Physics, PEOPL'S REPU⿴囗十⺝ IC OF CHIN

cibrarian, Institute of Phrs., PEOPLE's REPU⿴囗十 IC OF CHIMA

Library. Tsing Hud University. PEOPLE'S REPUBLIC OF CAINA
Z. Li, Southwast inst. Physies, PEOPLE'S REPUBLIC OF CHINA Prof. J.A.C. Cabral, Inst Suparior Tecnico, PORTUGAL

Dr. Octavian fetrus, AL I CUZA University, ROMANIA

Dr. Jehan de Villiers, Fusion \$tudies, AEC, SO AFRICA

Prof. M.A. Hellbarg, University of Natal, SO AFRiCA

C.I,E,M.A.T., Fusion Div, Library, SPAIN

Or. Lemnart Stent10, University of UMEA, SWEDEN

Library, Royal Inst Toch, SWEDEN

Prof. Hans WIIhtimson, Chalmers Univ Tech, SWEDEN

Centre Phys des Plasmas, Ecole Pelytech fed, SwitzerLand

Bibliotheak, Fom-inst Voor PIssmb-Fysico, THE HETHERL ANOS

Dr. D.D. Ryutov, SIberian Acad Sci, USSR

Or. G.A. El iseev, Kurchatov Institute, USSR

Dr, V,A. Glukhikh, Inst Electrophysical Apparatus, USSR

Or. V,T. Tolak, Inst, Phys. Tech. USSR

Or. L.M. Kovrizhnykh, Institute Gen. Physics, USSR

Nuclear Res. Establ:shment, Julich Ltd., W. GERMANY

Blaliothek, Inst. Fur PIasmaforschung, W. GERMANY

Dr. K. Schindler, Ruhr Univarsitat Bochum, W. GEPMANY

ASDEX Reading Rom, IPPAMax-PI anck-Institut fur

Plasmaphys/k, W. GEFany

Librarian, Max-Planck institut, W. GERaAnY

Prot, R.K. Janev, Inst Phys, YugosLavia 